\title{
Study of the Biodegradation of a Polymer Derived from Castor Oil by Scanning Electron Microscopy, Thermogravimetry and Infrared Spectroscopy
}

\author{
José M. Cangemi, Salvador Claro Neto, Gilberto 0. Chierice \\ Instituto de Química de São Carlos, USP \\ Antonia M. dos Santos \\ Instituto de Biociências, UNESP-Rio Claro
}

\begin{abstract}
The aim of this research is to study the biodegradation of a polyurethane derived from castor oil, which contains polyester segment in its molecular structure, thus becoming susceptible to the microorganisms attack. The biodegradation of polyurethane was tested in contact with microorganisms resulting from microbiological grease degrading agents, in appropriate liquid media, with a duration of 156 days. The study was done by using scanning electron microscopy (SEM), thermogravimetry (TG) and Fourier-transform infrared spectroscopy with accessory for attenuated total reflectance (FTIR-ATR). The results suggest that the degradation of polyurethane derived from castor oil occurs. TG curves are used in order to indicate the biodegradation, showing changes between the thermal behavior of the samples that were inoculated with microorganisms and control. In the FTIR-ATR spectra, there are detectable changes between the spectra of control and attacked specimens; this suggests that degradation occurs, with the decreased intensity of the absorption band at $1042 \mathrm{~cm}^{-1}$, corresponding to the esters links.
\end{abstract}

Keywords: Biodegradation, polyurethane, castor oil, thermogravimetry, infrared spectroscopy.

\section{Introduction}

The use of plastic is growing due to the new and numerous applications that are frequently emerging. Many factors are responsible for this evolution, such as cost and durability. American statistics point that 160 tons of solid wastes are annually thrown into the environment, of which $6 \%$ to $7 \%$ are plastic waste, representing about $30 \%$ of the total volume ${ }^{[1]}$.

One of the polymers that have been more used is the polyurethane foam. The synthesis of urethane involves the reaction of functional groups isocyanate with hydroxyl functional groups.

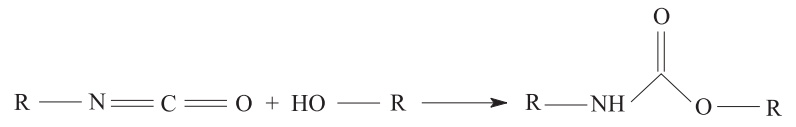

This reaction, discovered in 1848 by Wurtz ${ }^{[2]}$, was only been applied in the $40^{\prime} \mathrm{s}$, when Bayer ${ }^{[3]}$ developed in Germany the first polyurethanes.

This process occurs when we react a compound formed by two or more isocyanate in its structure with a poliol, or, in other words, a multi functional alcohol.

Observing our everyday lives we will find the polyurethanes in many places, as in chair upholstery, automobiles, shoes, clothes, mattresses, in electronic insulation (high voltage nets, telephone wires, electronic equipment, etc.), in terminal isolations (refrigerators, freezers, etc.), acoustic isolations, paint, etc. and its most recent application that has been studied by different researchers ${ }^{[4]}$, which is the usage of polyurethane as a biomaterial.

The market for PU's, mentioned above, had in 2002 an annual consumption of 10,1 million tones, with a prevision of 11,6 million tones in 2006. Nowadays, PU's occupy the sixth position the market of the best-sold plastic in the world, with about $5 \%$ of the market ${ }^{[5]}$. These foams are generally produced with products derived from petroleum, which besides not being renewable resources; they produce products that are not biodegradable. Because of its persistence in the environment and of the diminishing of authorized areas to receive them (and consequently a raising of cost) plastic became a problem to the environment.

Nowadays there are two tendencies in the environment field concerning the development of "ecologically correct" plastics. One of them would be renewable plastics and the other the usage of biodegradable plastics. Although they are very used, the recycled plastics have the inconvenience of presenting a recycling limit, becoming an aggressive waste to the environment. The biodegradable plastics have a more ecological behavior, because as they decompose, they totally integrate with the environment.

Corresponding author: José M. Cangemi, Instituto de Química de São Carlos, USP, Av. Dr. Carlos Botelho 1465, CEP:13560-970, São Carlos, SP, Brasil. E-mail:mcangemi@iqsc.usp.br 
Biodegradation or biological degradation consists of those processes resulted by the attack of determined compounds or material by live organisms, such as bacteria, fungus, insects and rodents. The term is restricted to the degradation caused by microorganisms ${ }^{[6]}$. Biodegradable plastics open new horizons to novel considerations in the treatment of wastes, once these materials can be degraded under environmental conditions and enable the biological treatment of wastes, in a town or industry ${ }^{[7]}$.

The Group of Analytic Chemistry and Technology of Polymers from USP - São Carlos has developed a kind of foam that differs from the others for it is derived from castor oil, which is a renewable resource of natural origin; the castor oil is a compound of approximately $90 \%$ of triglyceride of the ricinoleic acid, which structure is as follows, is obtained from the seeds of the plant "Ricinus Communis", found in tropical and subtropical areas, being abundant in Brazil.

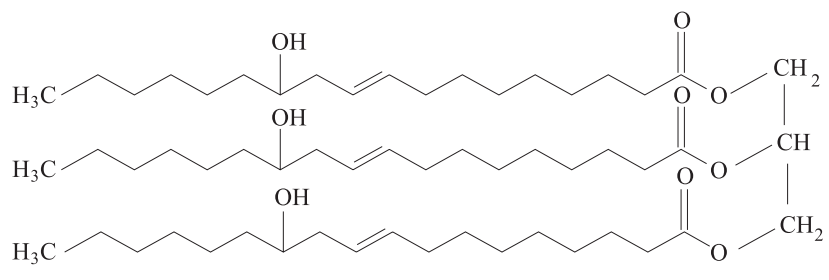

Triglycerides of ricinoleic acid

One of the most striking properties of the castor oil, because of the hydroxyl in the carbon 12, is the fact that it is considered a trifunctional polyol polyesther ${ }^{[8]}$. These characteristics make the castor oil become a basic natural resource in the synthesis of polyurethane, being possible to obtain a great variety of polyols that substitute the ones derived from petroleum.

In this research, it is studied the biodegradation of the foam mentioned by using cultivation of microorganisms derived from biological grease-degrading agents. The biodegradation was analyzed through scanning electron microscope (SEM), thermogravimetry (TG) and Fourier-transform infrared spectroscopy with accessory for attenuated total reflectance (FTIR-ATR).

\section{Experimental}

\section{Microorganisms}

The microorganisms used in the tests were extracted from marketed biological agents, used for the degradation of grease, as follows:

- Fungi Aspergillus sp, extracted from Bacgor, produced by Biobac Biotecnologia Indústria e Comércio Ltda, whose species has not yet been identified. These fungi are referred to as Fun 1 and Fun 5 in the study.

- Bacteria Chryseobacterium meningosepticum, extracted from Bacgor, produced by Biobac Biotecnologia Indústria e Comércio Ltda, referred to in the study as Bac 1.

\section{Isolation of microorganisms}

The microorganisms were isolated by using the method of surface sowing, with the help of a Drigalski handle.

\section{Cultivation media}

The microorganisms were cultivated in a $30^{\circ} \mathrm{C}$ plate, in a Saboraud solid-media, with the following composition (per liter): dextrose, $40 \mathrm{~g}$; peptone, 10; agar, $17 \mathrm{~g}$.

\section{Media for inoculation and degradation}

Media containing $0,1 \mathrm{~g} \mathrm{NH}_{4} \mathrm{H}_{2} \mathrm{PO}_{4}, 0.02 \mathrm{~g}$ of $\mathrm{KCl}, 0.02 \mathrm{~g}$ of $\mathrm{MgSO}_{4} .7 \mathrm{H}_{2} \mathrm{O}, 0.3 \mathrm{~g}$ of yeast extract and $100 \mathrm{ml}$ of distillated water. The $\mathrm{pH}$ was adjusted in 7.8.

\section{Polymeric material}

In this research was used natural polyurethane foam derived from castor oil, made by the Group of Analytic Chemistry and Technology of Polymers from USP-São Carlos, and also conventional foam, produced by Indústria e Comércio Santa Maria Ltda.

The samples of polyurethane were cut in $3.0 \mathrm{~cm}$ length and $1.0 \mathrm{~cm}$ of diameter, and were sterilized in autoclave for 20 minutes at $127^{\circ} \mathrm{C}$ and $1 \mathrm{~atm}$. After it was put in a media to inoculation and degradation where the samples were treated during 156 days in ambient temperature, and after they were washed with distillated water many times and dried by using a vacuum desiccator. The dried samples were used for subsequent analyses.

\section{Thermogravimetric analysis (TGA)}

The physical-chemical characterization was made by using a thermobalance Du Pont, model (TGA) 951 attached to a thermoanalyser TA 2000. The thermogravimetric curves were obtained according to the following conditions ${ }^{[9]}$ : samples of approximately $5 \mathrm{mg}$, temperature range of 30 to $750{ }^{\circ} \mathrm{C}$, heating rate of $10^{\circ} \mathrm{C} / \mathrm{min}$ and atmosphere of $\mathrm{N}_{2}$ (dynamic) of $100 \mathrm{~cm}^{3} / \mathrm{min}$.

\section{Infrared spectroscopy with accessory for attenuated total reflectance (FTIR-ATR)}

Surface chemical groups of the control and degraded specimens were analyzed using a Bomem MB - 102 FTIR spectrometer in attenuated total reflection (ATR) mode using a ATR - 300 Spectra-tech Inc. accessory. FTIR-ATR spectra were averaged over 32 scans in the range of 300 and 4000 $\mathrm{cm}^{-1}$ wavenumbers, with a resolution of $4 \mathrm{~cm}^{-1}$.

\section{Scanning Electron Microscope (SEM)}

The polymer surfaces were examined under a scanning electron microscope (SEM) Topcon, model SM - 300.

\section{Results and Discussion}

\section{Thermogravimetry}

An important application of the thermogravimetric method is the study of the thermal behavior of the polymers. The TG curves provide information about the decomposition of different kinds of polymers ${ }^{[10]}$.

In reference to the study of biodegradation of $\mathrm{PU}$ foams, a controlling TGA curve was made of a sample that was submitted to cultivation media only, without microorganisms. 


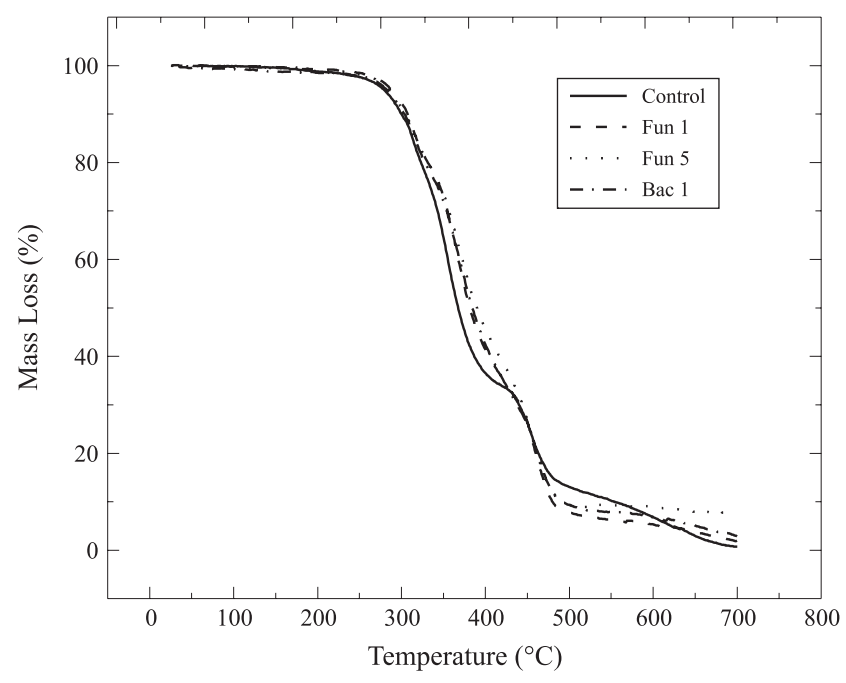

Figure 1. Thermogravimetric Curves for PU Foam Derived from Castor Oil Samples

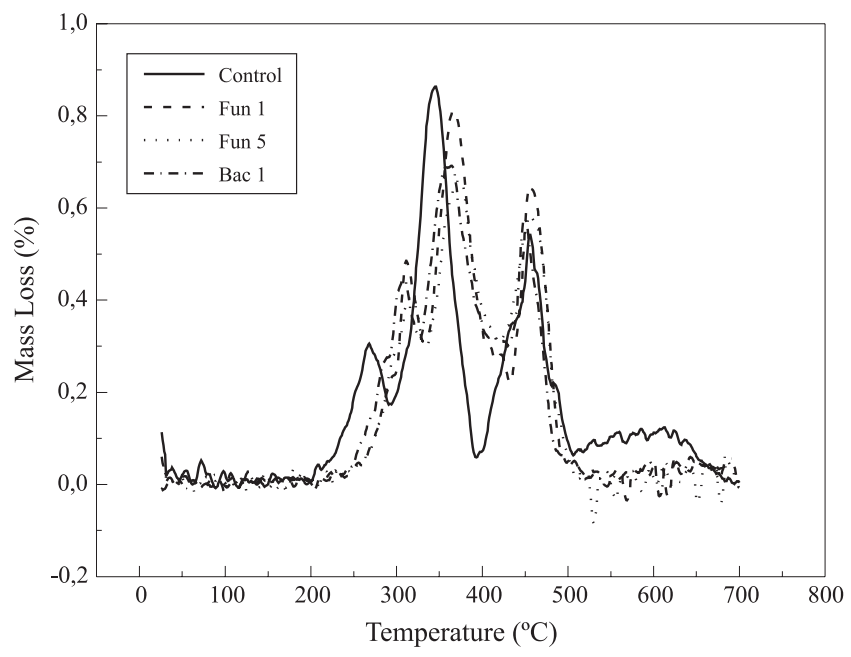

Figure 3. Derivative Thermogravimetric Curves for Vegetable Foam

Analyzing the controlling TG curve, the curve for the foams derived from castor oil (Figure 1), we can observe that the decomposition process occurs in three steps, showing a characteristic behavior of these PU's. According to ${ }^{[11]}$, the first step in decomposition of this polymer $\left(100\right.$ to $\left.300{ }^{\circ} \mathrm{C}\right)$ is related to the loss of volatile compounds, such as the additives used in the synthesis of polyurethane; the second step in decomposition of this polymer $\left(300\right.$ to $400{ }^{\circ} \mathrm{C}$ ) is related to the rupture of the urethane links, and the third step (400 to $500{ }^{\circ} \mathrm{C}$ ) is related to the rupture of the ester links. Comparing the thermogravimetric curves obtained with the samples attacked by the microorganisms to the controlling curve, we can observe that the third decomposition step of the polymer $\left(400\right.$ to $500{ }^{\circ} \mathrm{C}$ ) corresponds to the ester links that disappeared after the attack. In this study, the expectation was that the attack would predominantly occur in the ester group, since the microorganisms employed were fat degraders.

Analyzing the curve of thermal decomposition in conventional polyurethane (Figure 2), it can be observed that the curve occurs in two stages. Without knowing the

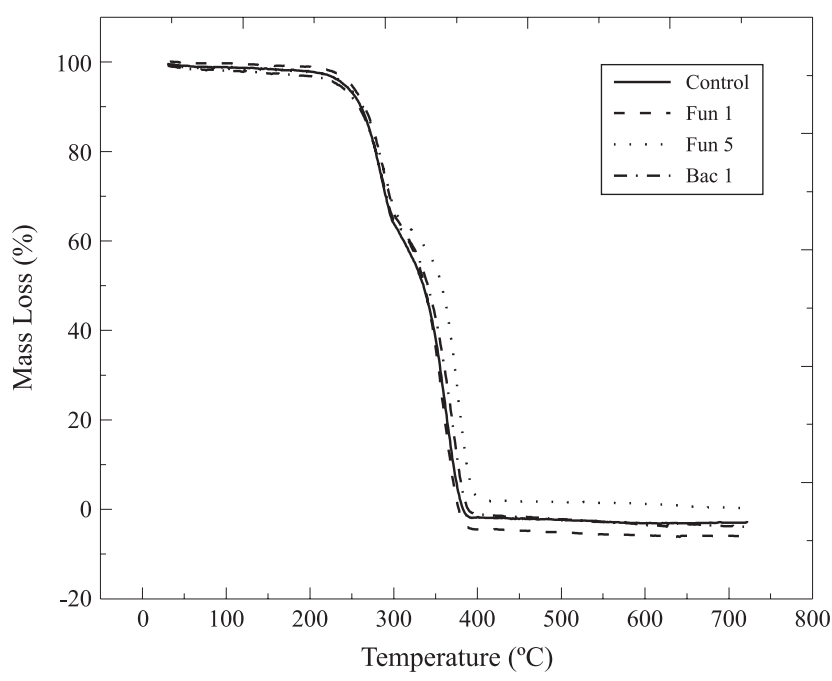

Figure 2. Thermogravimetric Curves for Conventional PU Samples

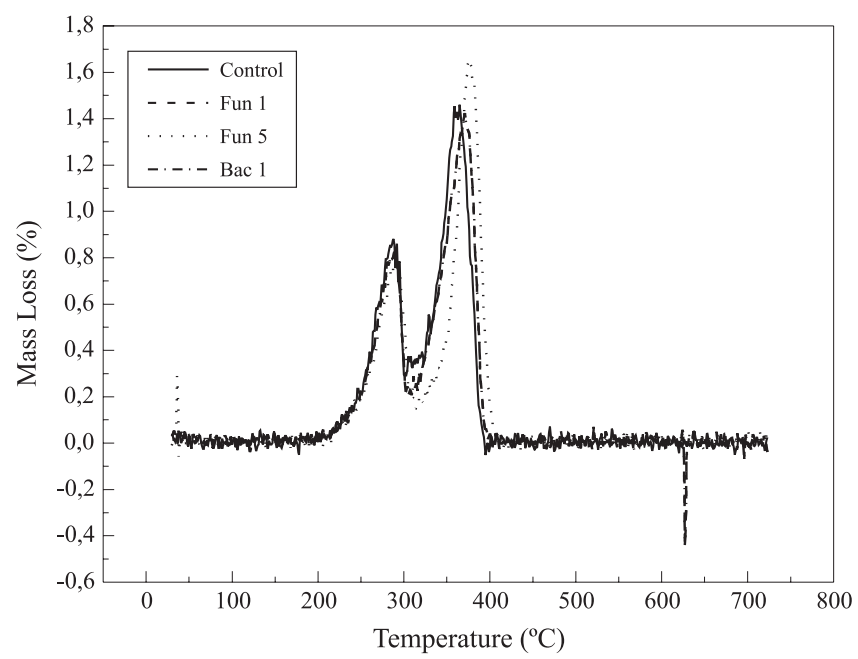

Figure 4. Derivative Thermogravimetric Curves for Conventional Foam

composition, it can be deduced that the first decomposition must be related to urethane links (200 to $300{ }^{\circ} \mathrm{C}$ ) and the second decomposition is related to the ether group. (350 to $450{ }^{\circ} \mathrm{C}$ ). When comparing the control to the samples exposed to microorganism attack, the absence of any indication that biodegradation has occurred can be observed, as there is almost no difference between the standard curve and the curves that represent the samples that underwent the attack.

Thermogravimetry used in this study was intended to relate loss of mass for the groups of interest, in this case, those that could be related to the effect of biodegradation. To facilitate a visualization of this effect, Figure 3 and 4 present, respectively, the derivations of the thermogravimetric curves of vegetable foam and conventional foam. The difference between the control curve and the curves of samples that underwent attack can be observed in the case of polyurethane of vegetable origin. This difference is practically imperceptible from the curves for conventional polyurethane.

In Table 1, to facilitate the interpretation of the process that occurred in the polyurethane foams, the ratio of percentage of 
Table 1. Mass loss of Chemical Group for Vegetable Origin Foam, Ratios of Urethane and Ester all in Percentages

\begin{tabular}{ccccc}
\hline Microorganism & Foam & \% Urethane & \% Ether & \% Urethane / \% Ether \\
\hline- & Vegetable Control & 45.00 & 29.68 & 1.516 \\
Fun 1 & Vegetable Biodegraded & 45.87 & 26.30 & 1.744 \\
Fun 5 & Vegetable Biodegraded & 45.45 & 21.93 & 2.072 \\
Bac 1 & Vegetable Biodegraded & 46.98 & 20.40 & 2.303 \\
\hline
\end{tabular}

Table 2. Mass loss of Chemical Group for Conventional Foam, Ratios of Urethane and Ether all in Percentages

\begin{tabular}{ccccc}
\hline Microorganism & Foam & \% Urethane & \% Ether & \% Urethane / \% Ether \\
\hline - & Conventional Control & 38.76 & 59.25 & 0.631 \\
Fun 1 & Conventional Biodegraded & 36.87 & 62.42 & 0.591 \\
Fun 5 & Conventional Biodegraded & 35.85 & 60.21 & 0.595 \\
Bac 1 & Conventional Biodegraded & 34.61 & 63.40 & 0.546 \\
\hline
\end{tabular}

loss of mass in the urethane group to the ester group (foam of vegetable origin) is presented. Table 2 presents the ratio of percentage of loss of mass in the urethane group to the ether (conventional foam). In Table 1 the increase of the ratio between the percentages is verified. This increase in the value of the ratio can be justified by the availability of the greater quantity of urethane group or the smaller quantity of ester links available to be degraded. In this case, the second hypothesis was chosen as the smaller quantity of ester available is related to the quantity of ester biodegraded by the microorganisms. The infrared spectra are presented in sequence, for the same foams analyzed by thermogravimetry, where it can be observed that the data add up to the previous data and indicate coherence in the results obtained up to this point.

\section{Infrared spectroscopy with accessory for attenuated total reflectance (FTIR-ATR)}

For reference, absorption spectra in the infrared region of the biodegradation of polyurethane foam were made of the control and samples that had undergone microorganism attack.

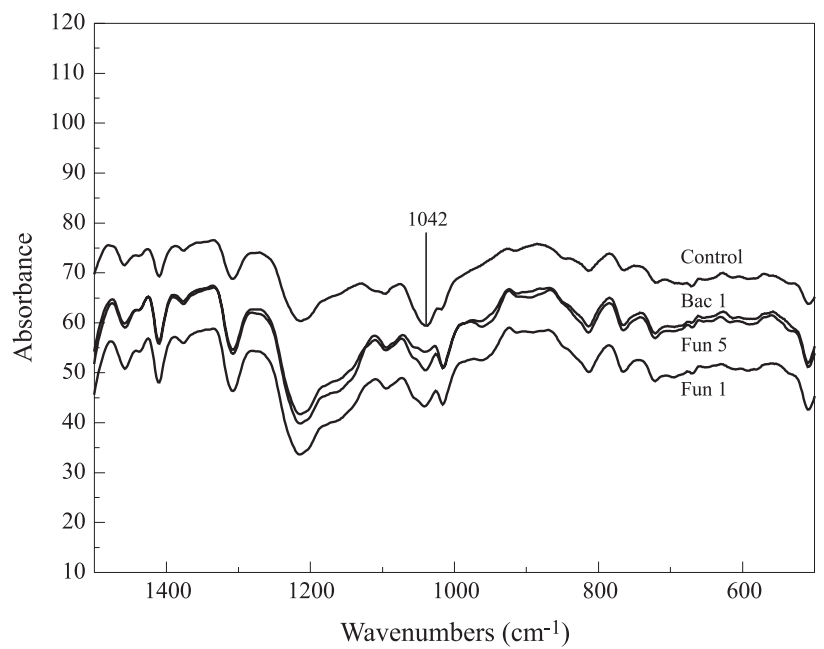

Figure 5. Comparison of Infrared Spectra for Control Sample and Polyurethane Foam Derived from Vegetable Origin Sample Subjected to Microorganism Attack
The results can be verified in Figure 5 and 6, where greater attention was given to the more important group bands analyzed in this study, which were the urethane link for both foams, the ester link for vegetable foam and the ether link for conventional foam.

Analyzing Figure 5, which refers to vegetable origin foam, between the spectra of the control sample and the samples which underwent microorganism attacks, the modification of greatest interest is the band located at $1042 \mathrm{~cm}^{-1}$, which diminished in intensity after the attack, indicating a process of biodegradation and a possible change in the structure of the polymeric material. In this region of the infrared spectrum, the so-called ester $\mathrm{C}-\mathrm{O}$ stretching vibrations are found ${ }^{[12]}$; whose occurrence shows the coherence of the results, considering that this mechanism is the same as utilized in the degradation of fats.

In the case of the ethers, the most important aspect of the IR is associated with the stretching vibration of the system $\mathrm{C}-\mathrm{O}-\mathrm{C}$. The more characteristic absorption of the aliphatic ether spectrum is an intense band in the region of 1150 to

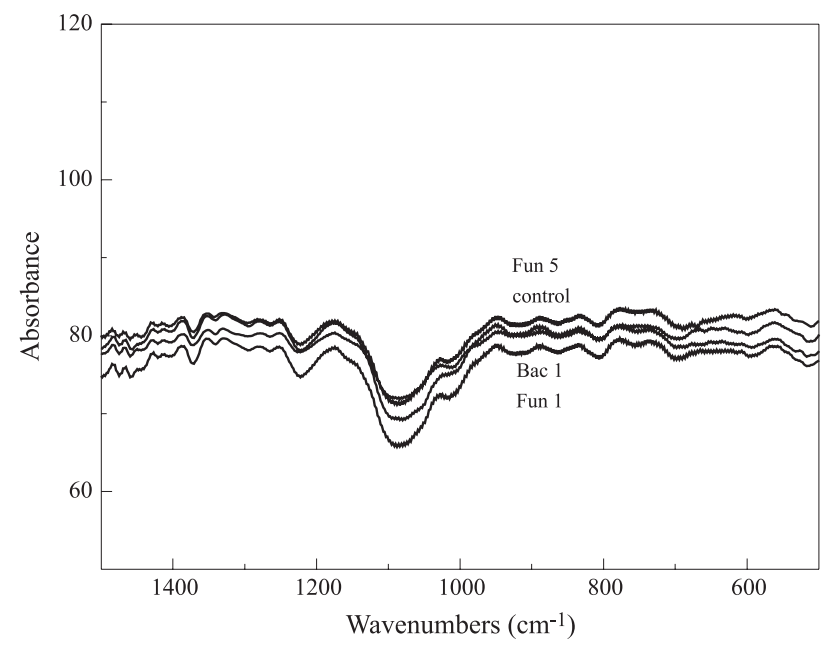

Figure 6. Comparison of Infrared Spectra for Control Sample and Conventional Polyurethane Foam Sample Submitted to Microorganism Attack 


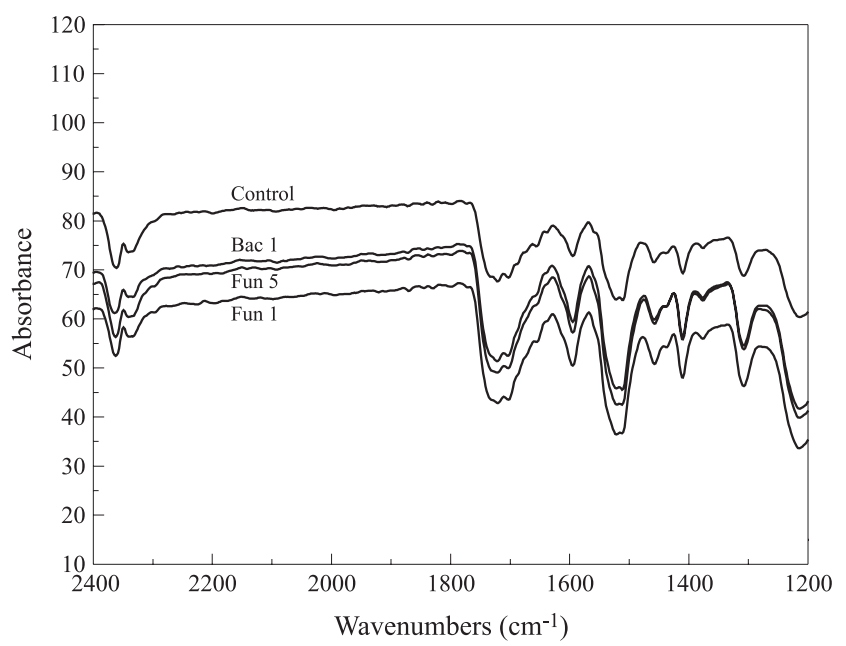

Figure 7. Comparison of Infrared Spectra for Control and Vegetable Origin Polyurethane Samples Subjected to Microorganism Attack

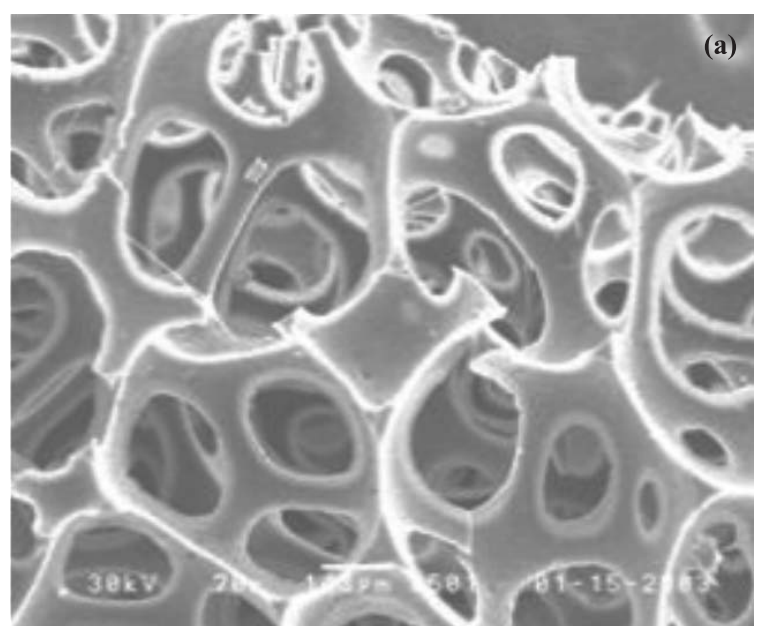

Figure 9 (a). PU Foam Derived from Castor Oil: Control in Media without microorganisms $(70 \mathrm{x})$

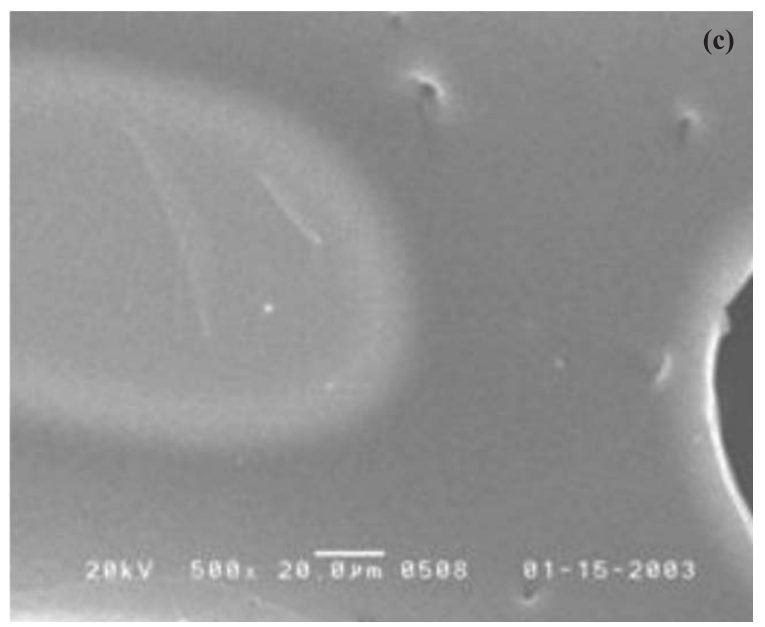

Figure 9 (c). Sample Subjected to Fun 5 Microorganism Attack (500 x)

$1085 \mathrm{~cm}^{-1}$. Analyzing Figure 6, the absence of modifications between the standard curve and the polymer curves after the attack by microorganisms, demonstrates the maintenance of

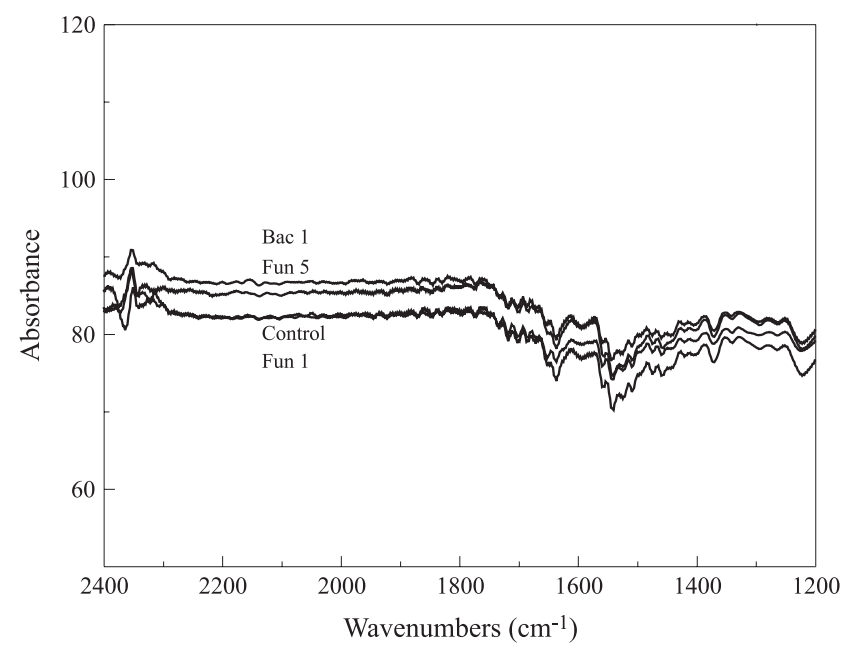

Figure 8. Comparison of Infrared Spectra for Control and Conventional Polyurethane Foam Samples Subjected to Microorganism Attack

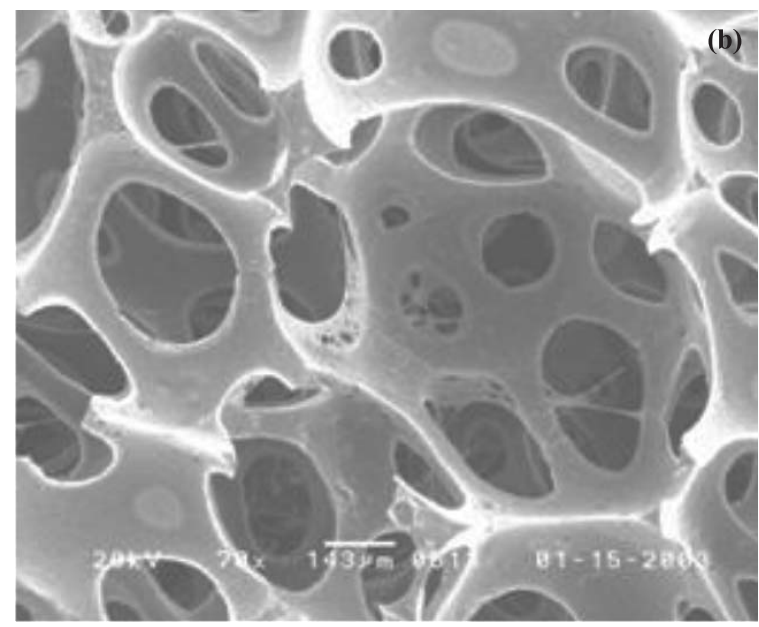

Figure 9 (b). Sample Subjected to Fun 5 Microorganism Attack (70 x)

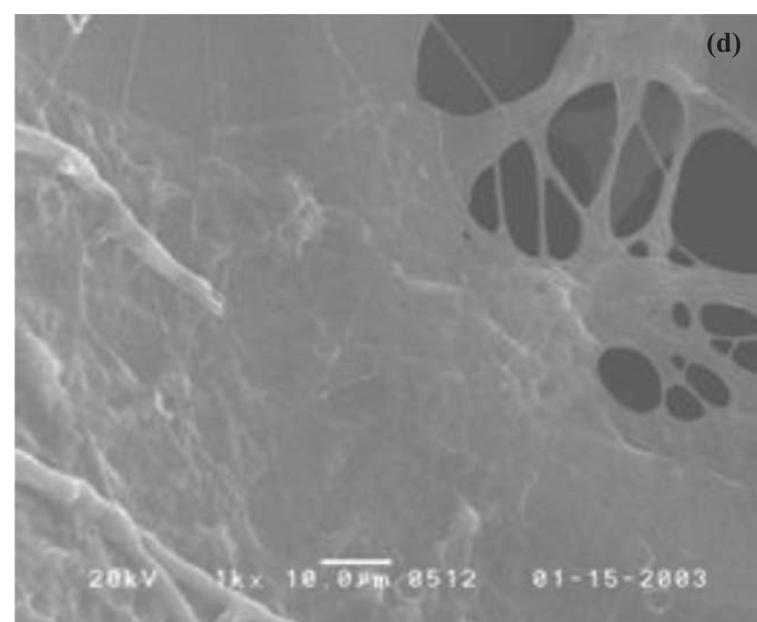

Figure 9 (d). Sample Subjected to Fun 5 Microorganism Attack (1000 x)

the macromolecular structure and as such, the absence of biodegradation.

According to Claro Neto ${ }^{[11]}$, a characteristic band of the 


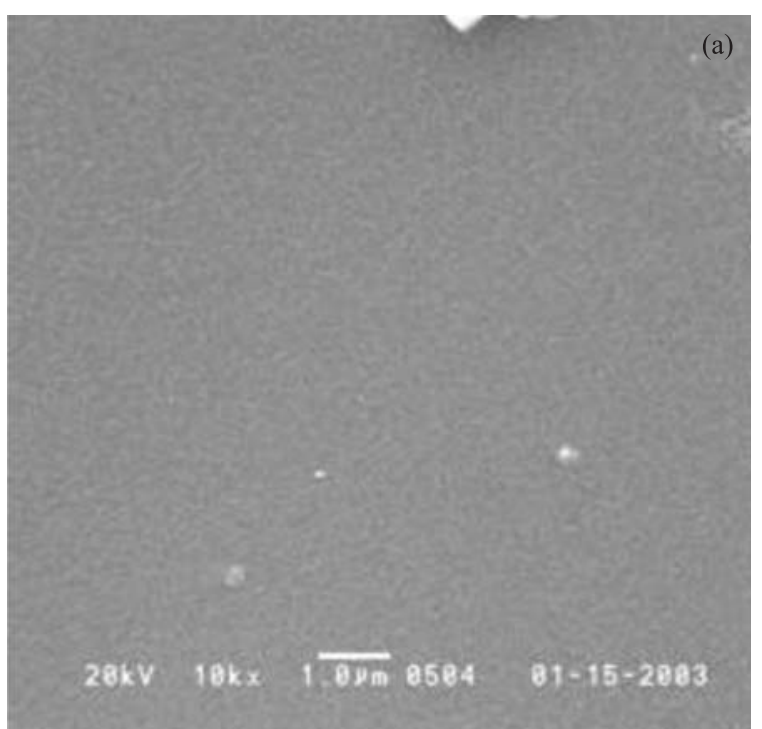

Figure 10 (a). PU Foam Derived from Castor Oil: Sample in Media without Microorganisms $(10000 \mathrm{x})$

isocyanate group to the region of $2230 \mathrm{~cm}^{-1}$ can be observed in the pre-polymer and a urethane band around $1700 \mathrm{~cm}^{-1}$ and $1500 \mathrm{~cm}^{-1}$, that are related to the stretches $\mathrm{C}=\mathrm{O}$ e N-H, respectively. In Figures 7 and 8 are found spectrums for this interval, permitting analysis of characteristic chemical groups for this region. As can be observed, there is no indication of biodegradation in this region as there is no change in the intensity of the bands. This reinforces the conclusion obtained with the data in Table 1, where the increase in the value of the percentage of urethane to percentage of ester is due to reduction of the quantity of ester links, due to the action of the microorganisms.

\section{Scanning Electron Microscope (SEM)}

The results obtained through the thermal analysis, to the PU foam derived from castor oil samples were confirmed by subjecting them to the same analysis in scanning electron microscope (SEM). The samples were cultivated during 156 days in ambient temperature.

In Figure 9 (a) we can observe the SEM correspondent to the standard of the PU foam derived from castor oil, which was put in a media without microorganisms and where there was no attack. In Figure 9 (b) we can observe the SEM correspondent to the sample that was put in a media with microorganisms FUN 5, where an attack occurred. Comparing the two pictures, we can observe two basic differences, which indicate the biodegradation: the picture corresponding to the sample that suffered the attack presents smaller erosion areas on the cells' walls, where there is the presence of whitish regions, which are found in Figure 9 (c), as the presence of greater erosion regions, which are similar to webs, as shown in Figure 9 (d).

In Figure 10, we present the SEM photomicrographs showing the surface topography of the sample before and after microorganism attack. It can be clearly seen from Figure 10 (a) for control sample that the sample surface is smooth.

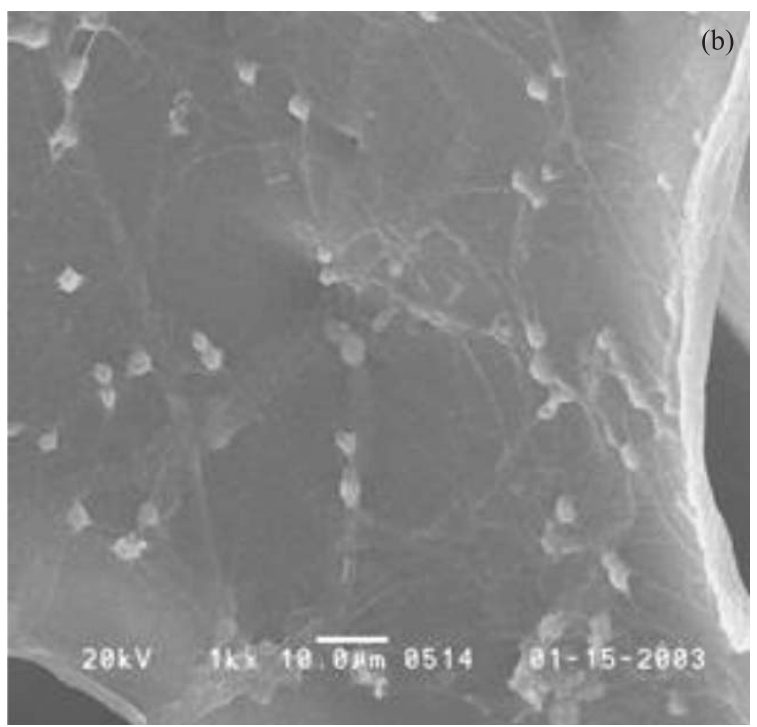

Figure 10 (b). Sample Subjected to Bac 1 Microorganism Attack (1000 x)

However, after exposure to the microorganism FUN 6, the surface of the sample as shown in Figure 10 (b) becomes rougher.

\section{Conclusions}

Utilizing qualitative (FTIR-ATR and SEM) and quantitative (TG) techniques, the polyurethane foam control sample was compared to the polyurethane submitted to microorganism attack. In relation to the vegetable origin foam, it can be noted that:

- In the TG and DTG curves, Figures 1 and 3, respectively, a difference can be observed between the thermal behavior of the control and the samples attacked by microorganisms, principally in the third step of decomposition ( 400 to $500{ }^{\circ} \mathrm{C}$ ), which correspond to ester links;

- The increase in ratios between the mass loss in the control foam and those submitted to microorganisms attack was increased by the attack (Table 1). This increase was probably due to the smaller quantity of available ester, which had been degraded by the microorganisms during the experiment;

- The preceding fact is proven by the infrared spectrum bands (Figure 5), by the diminution of intensity in the band at $1042 \mathrm{~cm}^{-1}$, a characteristic region for axial deformation in ester;

- In the SEM photomicrographs analysis of the sample surface, it can be observed before the attack [Figures 9 (a) e 10 (a)], the samples showed a smooth surface. After the attack by microorganisms, the surface of the specimens as show in Figures 9 (b-d) and 10 (b) becomes rougher.

The results presented by the analyses demonstrate coherency, taking into account that this mechanisms is the same used by the microorganisms in the degradation of fats, in other words, the attack on ester links by microorganisms ${ }^{[13,14]}$. The property of resin derived from castor oil should facilitate the actions by microorganisms tested. 
When the same tests were made on conventional foam (non - vegetable source), no change was observed between the control and the samples attacked, therefore affirming that the conventional foam is not biodegradable ${ }^{[15]}$. It can be concluded that the great advantage of vegetable origin foam over conventional foam, is due to the fact that it is biodegradable, which confers a more ecological behavior in relation to the environment. This degradation can be attributed to the microorganism action.

\section{Acknowledgements}

To Capes, for financial assistance. To Professor Dr. Mário Cilense, Departamento de Físico-Química do Instituto de Química da UNESP - Araraquara, who kindly helped with the SEMs shown in this study. To Professor Dr. Carlos Henrique G. Martins and his staff at the Laboratório de Pesquisas Microbiológicas, UNIFRAN (Universidade de Franca), for assistance in the identification of microorganisms utilized in this study.

\section{References}

1. Souza; J. P. - Plástico Moderno, 230, p. 15 (1993).

2. Wurtz, A. Liebigs, J. - Ann. Chem., 71, p. 326 (1849).

3. Oertel, G. - "Polyurethane Handbook", Hanser Publisher, Munich (1985).

4. Woods, G. - "The ICI Polyurethane Book", John-Wiley, New York (1987).

5. Vilar, W. D. - "Química e Tecnologia dos Poliuretanos", Vilar Consultoria Técnica Ltda, Rio de Janeiro (2000)..

6. Kelen, T. - "Polymer Degradation", Van Nostrand Reinhold Company, New York (1983).
7. Abou-Zeid, D. -M. - "Anaerobic Biodegradation of Natural and Synthetic Polyesters", Tese de Doutorado, Universidade de Tecnologia Carolo-Wilhelmina, Alemanha (2001).

8. Chierice, G. O. \& Claro Neto, S. - In: O Agronegócio da Mamona no Brasil, Azevedo, D. M. P., Lima, E. F. (ed.), Embrapa , Brasília (2001).

9. Brown, M. E. - "Introduction to Thermal Analysis", Chapman \& Hall, Londres (1988).

10. Skoog, D. A. \& Leary, J. J. - "Principles of Instrumental Analysis", Saunders, New York (1992).

11. Claro Neto, S. - "Caracterização Físico-química de um Poliuretano Derivado de Óleo de Mamona Utilizado para Implantes Ósseos", Tese de Doutorado, Universidade de São Paulo, Brasil (1997).

12. Silverstein, R. M. \& Webster, F. X. - "Identificação Espectrométrica de Compostos Orgânicos”, LTC Livros Técnicos e Científicos S.A., Rio de Janeiro (2000).

13. Glazer, A. N. \& Nikaido, H. - "Microbial Biotechnology, Fundamentals of Applied Microbiology", Freeman and Company, New York (1994).

14. Wong, D. W. S. - "Food Enzymes - Structure and Mechanism", Chapman \& Hall, New York (1995).

15. Luo, S. \& Netravali, A. N. - Polymer Degradation and Stability, p.80 (2003)

Enviado: 01/02/06

Reenviado: 28/04/06

Aprovado: 10/05/06 